\title{
Effectiveness of Micro- and Nanomaterials in Asphalt Mixtures through Dynamic Modulus and Rutting Tests
}

\author{
Hui Yao and Zhanping You \\ Department of Civil and Environmental Engineering, Michigan Technological University, 1400 Townsend Drive, \\ Houghton, MI 49931, USA
}

Correspondence should be addressed to Zhanping You; zyou@mtu.edu

Received 7 September 2015; Accepted 16 December 2015

Academic Editor: Domenico Acierno

Copyright (C) 2016 H. Yao and Z. You. This is an open access article distributed under the Creative Commons Attribution License, which permits unrestricted use, distribution, and reproduction in any medium, provided the original work is properly cited.

The objectives of this research are to use micro- and nanomaterials to modify the asphalt mixture and to evaluate the mechanical performance of asphalt mixtures. These micro- and nanomaterials, including carbon microfiber, Nanomer material, nanosilica, nonmodified nanoclay, and polymer modified nanoclay, were selected to blend with the control asphalt to improve the overall performance of the modified asphalt binders and mixtures. The microstructures of original materials and asphalt binders were observed by the field emission scanning electron microscope (FE-SEM). The mixture performance tests were employed to evaluate the resistance to rutting and permanent deformation of the modified asphalt mixtures. Test results indicate that (1) the dynamic modulus of micro- and nanomodified asphalt mixtures improved significantly; (2) the rutting susceptibility of the modified asphalt mixtures was reduced significantly compared to that of the control asphalt mixture; (3) the microstructures of modified asphalt binders were different from the control asphalt, and the structures determine the improvement in the performance of modified asphalt mixtures. These results indicate that the addition of micro- and nanomaterials enhanced the rutting performance and strength of asphalt mixtures. In addition, the analysis of variance (ANOVA) was used to analyze the modifying effects of microand nanomaterials on the performance.

\section{Introduction}

In the process of asphalt modification, different materials have been utilized to modify the base asphalt and to improve the pavement and mechanical performance of asphalt binders and mixtures. These materials include the styrene-butadienestyrene (SBS) [1-3], lime [4, 5], crumb rubber [6], biooil [7], and electronic waste powders [8]. Generally speaking, the SBS modifier was commonly used in the pavement field and the property of SBS modified asphalt was examined by the dynamic shear rheometer (DSR), rotational viscometer (RV), indirect tensile test (ITT), Fourier Transform Infrared (FTIR) spectroscopy, and environmental scanning electron microscope (ESEM) $[1-3,9]$. The copolymer SBS modified asphalt binder underwent an obvious degradation during the aging time (after short-term aging), but SBS did not resist aging, and the addition of antioxidants delays the oxidation of asphalt binders [1]. The moisture susceptibility of the SBS modified asphalt mixture decreased relative to the control asphalt mixture [2]. The ESEM images showed that the adhesion properties between the SBS modified asphalt binder and aggregates improved and the horizontal plastic deformation rates of modified asphalt mixtures decreased [3]. Lime has been applied to improve the moisture susceptibility of asphalt mixtures for many years. The mild aging of asphalt is also useful for the improvement of moisture susceptibility $[4,5]$. The crumb rubber was usually produced from the waste tires. The crumb rubber was also used to improve the high-temperature performance of the asphalt and mixtures. This utilization also expanded the usage of waste tires and reduced the environmental impacts [6]. In addition, swine biooil was used to enhance the low temperature of asphalt [7], and the electronic waste powders were also processed to modify the asphalt to improve the resistance to rutting and the environmental issues [8].

The utilization of nanomaterials is also a promising method to increase the performance of asphalt mixtures due to many special and unique characteristics of nanomaterials. 
It is reported that the nanomaterials were applied to enhance the pavement performance of the asphalt binders, such as carbon nanofibers (CNFs), carbon nanoparticles, subnanosized hydrated lime, nanoclay, and nano- $\mathrm{SiO}_{2}$. The data shows that the fatigue life and rutting resistance of CNFs modified binders were enhanced $[10,11]$. The carbon nanoparticles at different amounts were used to modify the asphalt binders, which were from five different binder sources. The failure temperature and creep recovery properties of the modified asphalt binders were investigated. The complex shear modulus and failure temperature of the modified asphalt binders increased. In addition, the source of the asphalt greatly affected the performance of modified asphalt [12]. A subnanosized hydrated lime (SNHL), produced from regular hydrated lime (RHL), was selected as an additive to strengthen the moisture susceptibility of WMA. The microstructure pictures (size, shape, and texture) of the crushed lime were observed by a scanning electron microscope (SEM). The indirect tensile strength (ITS) and tensile strength ratio (TSR) were examined to assess antistripping properties and moisture damage of the modified asphalt mixtures. These test results show that the ITS and TSR of WMA with SNHL increased slightly compared to the WMA with RHL. This proves that the size of the modifiers affects the performance of the asphalt binder and mixture [13]. The nonmodified nanoclay (NMN) and polymer modified nanoclay (PMN) were used to modify the base asphalt. The viscosity, shear modulus, and microstructure of the modified asphalt binders were examined $[14,15]$. The nano- $\mathrm{SiO}_{2}$ (silicon dioxide) and SBS were used together to improve the pavement performance of asphalt. The data showed that the asphalt mixture modified by $5 \% \mathrm{SBS}$ and $2 \%$ nano- $\mathrm{SiO}_{2}$ enhanced the mechanical properties of mixtures [16].

Normally, some common materials are selected to improve the performance of asphalt mixtures. However, the overall performance of asphalt mixtures has not been significantly increased compared to the control asphalt. Therefore, it is permissible to use the other materials/nanomaterials to modify the asphalt to obtain a better performance of the asphalt mixtures, especially the other materials that are already applied to improve the properties of composite materials in other fields, such as areas in physics or chemistry. It is well known that the carbon fibers enhance the strength and modulus of composite materials [17-19]. The Nanomer material maintains good heat stability and electrochemical performance of the composite materials [19]. The nanosilica presents good dispersions and high stability of the composite materials [20, 21]. The polymer modified nanoclay may improve the tear and compressive strengths of the composite materials $[15,22,23]$. The nonmodified nanoclay can be applied to improve the mechanical performance and heat resistance of the composite materials [15, 24]. All microand nanomaterials mentioned above are used to successfully improve the performance of composite materials in different industrial fields. Likewise, the hypothesis is to use these materials for asphalt modification. Based on the literature review, these micro- and nanomaterials were barely used in the modification of asphalt mixtures. Therefore, in this research, the carbon microfiber (MCF), Nanomer material, nanosilica
(NS), nonmodified nanoclay (NMN), and polymer modified nanoclay (PMN) were selected and added to the control asphalt. The modified asphalt binders and aggregates were mixed and compacted according to the Superpave specifications. The dynamic modulus and asphalt pavement analyzer (APA) rutting tests were employed to evaluate the impact of the micro- and nanomaterials on the modification of asphalt.

\section{Research Objectives}

The objectives of this research are to use the micro- and nanomaterials to modify the asphalt mixture and to evaluate the pavement and mechanical performance of the modified asphalt mixtures. These micro- and nanomaterials, including carbon microfiber, Nanomer material, nanosilica, nonmodified nanoclay, and polymer modified nanoclay, were selected to blend with the control asphalt to improve the overall performance of the modified asphalt binders and mixtures. The microstructures of the micro- and nanomodified asphalt binders were examined by a Hitachi SU6600 field emission scanning electron microscope (FE-SEM) with a cryogenic stage. The microstructures of the control and modified asphalt binders may be helpful in explaining the amelioration of the performance of these modified asphalt mixtures. The asphalt mixture performance tests (dynamic modulus test and APA rutting test) were employed to evaluate the properties of micro- and nanomodified asphalt mixtures. Furthermore, the analysis of variance (ANOVA) was used to investigate the level of influence of micro- and nanomaterials on the performance test results.

\section{Materials Preparation and Microstructures of Micro- and Nanomaterials}

3.1. Control Asphalt Binder and Modifiers. The PG 58-34 control asphalt $\left(0.95 \mathrm{~g} / \mathrm{cm}^{3}-1.05 \mathrm{~g} / \mathrm{cm}^{3}\right)$ used in the research was obtained from Gladstone, Michigan, and modified by acrylonitrile butadiene styrene (ABS). Nanomer material (Figure 1) was produced by Nanocor Inc. in the USA and MCF (Figure 1) was shipped from Kureha Co. (Tokyo, Japan). Nanomer is a kind of montmorillonite clay with a surface modification, and it has a platy structure. It features a density of $0.251 \mathrm{~g} / \mathrm{cm}^{3}$ and an aspect ratio of $200-400 \mathrm{~nm}$. The data is from the Nanocor Company. Carbon microfiber has a chiral structure and is produced from petroleum pitch. The tensile strength $(670 \mathrm{MPa})$ and elastic modulus $(30 \mathrm{GPa})$ are tested by the manufacturer $[18,19]$. Nanosilica was manufactured by the MTI Corporation (USA) without further treatment (Figure 1). The maximum size of nanosilica is about $30 \mathrm{~nm}$, and the surface area is around $440 \mathrm{~m}^{2} / \mathrm{g}$. Its bulk density is about $0.063 \mathrm{~g} / \mathrm{cm}^{3}[20,21]$. The nonmodified nanoclay (NMN), or the raw nanoclay (a kind of montmorillonite), is a 2-to-1 layered clay mineral and has a platy structure in which one of three dimensions stays at the nanolevel. Conversely, the polymer modified nanoclay (PMN) is nanoclay modified by polysiloxane (Figure 1). The polysiloxane oligomer chains are grafted on the surface of raw clay platelets, and one 


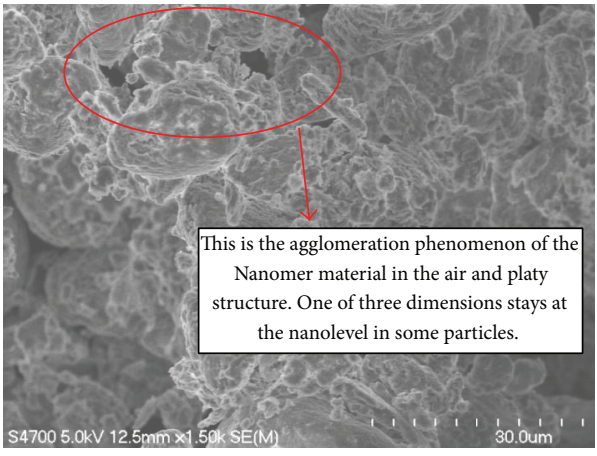

(a) The SEM image of Nanomer material [14]

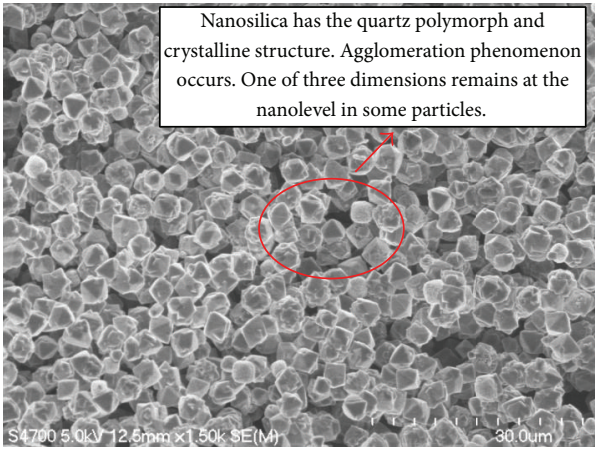

(c) The SEM image of nanosilica material

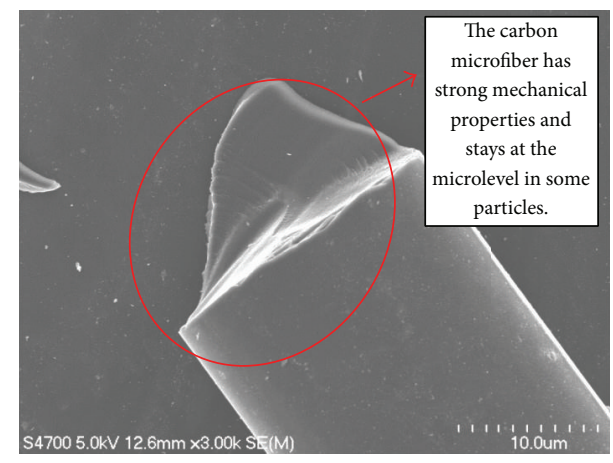

(b) The SEM image of carbon microfiber material

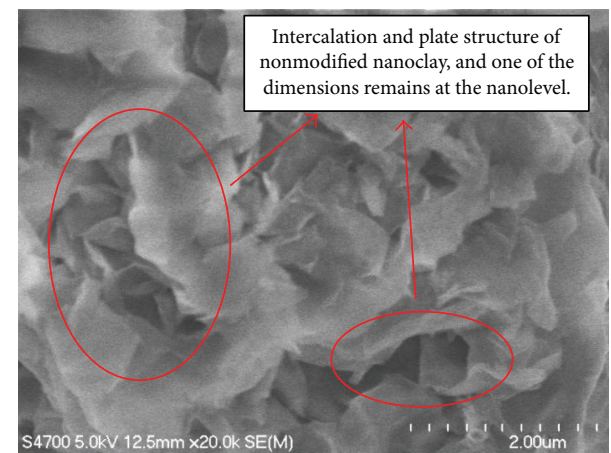

(d) The SEM image of NMN material [15]

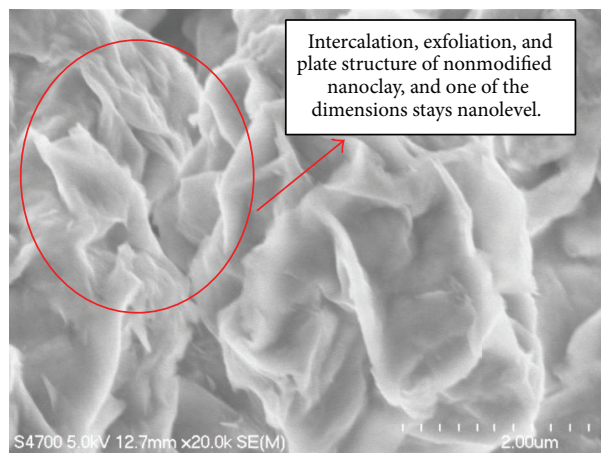

(e) The SEM image of PMN material [15]

FIGURE 1: The SEM images of Nanomer material, carbon microfiber, and nanosilica materials.

of three dimensions remains at the nanolevel. Therefore, PMN has a different microstructure than the nonmodified nanoclay. The micro- and nanomaterials ( $2 \%$ and $4 \% \mathrm{MCF}$, $2 \%$ and $4 \%$ Nanomer, $4 \%$ and $6 \%$ NS, $2 \%$ and $4 \%$ NMN, and $2 \%$ and $4 \%$ PMN) were blended with the control asphalt binder in the high shear mixer at the conditions of a $140^{\circ} \mathrm{C}$ temperature and $4000 \mathrm{rpm}$ speed, or even slightly higher temperatures and shearing speeds. The nanomaterials cannot be exposed to air for a long time due to the agglomeration phenomenon. After two hours of shearing and mixing, the modified asphalt binders were prepared for image testing and the evaluation of the performance. The properties of modified binders were discussed in the authors' previous papers. In this paper, the performance of modified asphalt mixtures will be mainly analyzed and discussed.
3.2. Aggregates and Mixture Gradation. The aggregates used in this study were shipped from Eagle River, Wisconsin. In accordance with the specifications of the Michigan Department of Transportation (MDOT), the 5E3 gradation of aggregates was used in this study and is shown in Figure 2. In accordance with the Superpave specification, a total of around 66 samples were used and compacted by the Superpave Gyratory Compactor (SGC). Before mixing with the asphalt, the aggregates were dried for at least two hours at the temperature of $165^{\circ} \mathrm{C}$. Based on the viscosities of micro- and nanomodified asphalt, the mixing and compaction temperatures were around $165^{\circ} \mathrm{C}$ and $155^{\circ} \mathrm{C}$, respectively. Simple performance tests (dynamic modulus and APA rutting tests) were used to evaluate the high-temperature performance of micro- and nanomodified asphalt mixtures. 


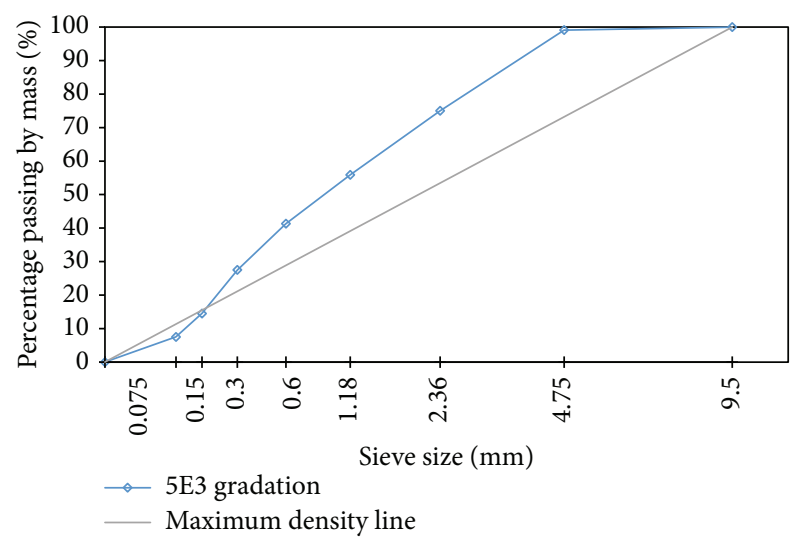

FIGURE 2: 5E3 gradation of the aggregates used in this study.

\section{Mixture Test Plan}

4.1. Dynamic Modulus Tests. The dynamic modulus is a main parameter of the asphalt mixture. The test results correlated with the permanent deformation and rutting performance of the asphalt pavement used the field effectively and efficiently compared to the other tests based on previous research [25-29]. In this study, the test was conducted under sinusoidal loading conditions. In accordance with the American Association of State Highway and Transportation Officials (AASHTO) TP62, an IPC universal testing machine was used to test the samples for the dynamic modulus (Figure 3 ). The test temperatures were $-10^{\circ} \mathrm{C}, 4^{\circ} \mathrm{C}, 21.3^{\circ} \mathrm{C}$, and $39.2^{\circ} \mathrm{C}$, and the test frequencies were $25 \mathrm{~Hz}, 10 \mathrm{~Hz}, 5 \mathrm{~Hz}, 1 \mathrm{~Hz}, 0.5 \mathrm{~Hz}$, and $0.1 \mathrm{~Hz}$. The voids of the test samples were around $7 \% \pm 0.5 \%$. In the test, the load levels were obtained from a trial test, and the recoverable strains were maintained between 75 and 125 microstrains. The phase angle and dynamic modulus of the asphalt mixtures were calculated by

$$
\begin{aligned}
\left|E^{*}\right| & =\frac{\sigma_{0}}{\varepsilon_{0}}, \\
\phi & =\frac{t_{i}}{t_{p}} \times 360,
\end{aligned}
$$

where $E^{*}$ is the dynamic modulus of asphalt mixtures, $\sigma_{0}$ is the applied stress, and $\varepsilon_{0}$ is the measured strain with linear variable displacement transducers (LVDTs); $\phi$ is the phase angle, $t_{i}$ is the time lag between the stress and strain cycle, and $t_{p}$ is the time of a stress cycle.

4.2. APA Rutting Test. The wheel tracking devices in the laboratory are typically designed to simulate a wheel rolling under a constant load on the asphalt mixture samples. The performance of the test samples is correlated to the performance of the field pavement. Based on the research reports $[25,26,30]$, there is an excellent correlation between the laboratory and field data. There are three main tests used in the laboratory wheel tracking devices (asphalt pavement analyzer, Hamburg wheel tracking device, and French rutting tester). In this study, the asphalt pavement analyzer was used to quantify the rutting resistance of micro- and nanomodified asphalt mixtures in accordance with AASHTO TP-63 (Figure 3). The testing temperature was $58^{\circ} \mathrm{C}$ with 8000 test cycles. The air voids of the samples were $4 \% \pm 0.5 \%$ and the dimensions were $75 \mathrm{~mm}$ high by $150 \mathrm{~mm}$ in diameter. The hose pressure in the APA was around $100 \pm 5$ psi, and the load of the wheels on the rubber hoses was $100 \pm 5 \mathrm{lb}$.

4.3. Microstructures of Raw Materials and Asphalt. The microstructures of micro- and nanomaterials modified asphalt binders were examined using a Hitachi SU6600 FE-SEM with a cryogenic condition. Liquid nitrogen was used to freeze the asphalt binder samples, and the test was conducted under the conditions of $\mathrm{a}-26^{\circ} \mathrm{C}$ temperature and $30 \mathrm{~Pa}$ pressure. The cryogenic stage in the SEM test was mainly prepared to minimize a heating issue caused by the $20 \mathrm{kV}$ electron beam. It is an effective and direct way to observe the microstructure of asphalt from SEM images. The microstructures of raw materials and asphalt binders also affect the macroscopic performance of asphalt and mixtures.

\section{Test Results and Discussions}

5.1. Dynamic Modulus Test Results. The dynamic modulus, a common property of the viscoelastic materials, is a ratio of stress to strain under the oscillatory forces applied to the tested materials. If purely elastic materials are tested, the strain of materials responds simultaneously; however, if purely viscous materials are tested, the strain lags stress by $90^{\circ} \mathrm{C}(\delta)$ in the phase lag difference. The dynamic modulus can be divided into the storage/elastic modulus $E^{\prime}$ and loss/viscous modulus $E^{\prime \prime}$. The storage part of the dynamic modulus represents the elastic portion, and the energy dissipated represents the viscous portion. The dynamic modulus of the micro- and nanomodified asphalt mixtures is shown in Figure 4 . The $E^{*} / \sin \delta$ comparison results of the micro- and nanomodified asphalt mixtures are also shown in Figures 5 and 6.

Figure 4(a) shows the dynamic modulus $E^{*}$ results of MCF modified and control asphalt mixtures at different contents. The dynamic moduli of MCF modified asphalt mixtures are significantly higher than those of the control asphalt mixture. The dynamic moduli of the $2 \%$ MCF modified asphalt mixture increase approximately by an average of $35 \%$ compared to the control asphalt mixture, and those of the $4 \%$ MCF modified mixture increase by an average of $28 \%$. At high temperatures, the dynamic moduli of the $4 \% \mathrm{MCF}$ modified asphalt mixture are marginally greater than those of the $2 \%$ MCF modified asphalt mixture as visible from the trend. However, the dynamic moduli of the $4 \% \mathrm{MCF}$ modified asphalt mixture are mildly lower than those of the 2\% MCF modified asphalt mixture at lower temperatures. This indicates that a high percentage of MCF in the modified asphalt mixture makes the mixture stiff at high temperatures and relatively soft at low temperatures. The rutting susceptibility and the potential of permanent deformation in the MCF modified asphalt mixtures may be reduced relative to the control asphalt mixture. As shown in Figure 7(a), the microstructure of MCF modified asphalt is different from 


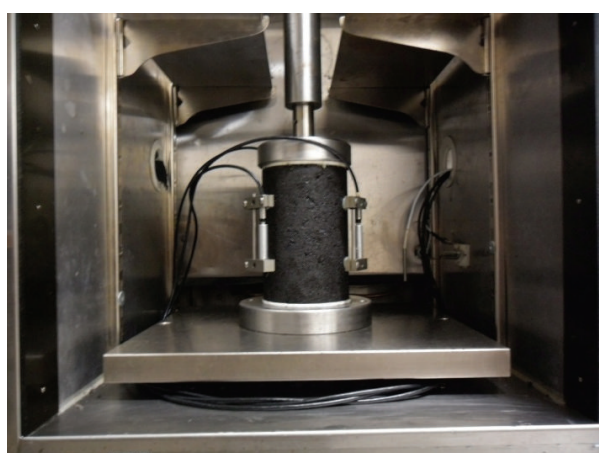

(a) Dynamic modulus test

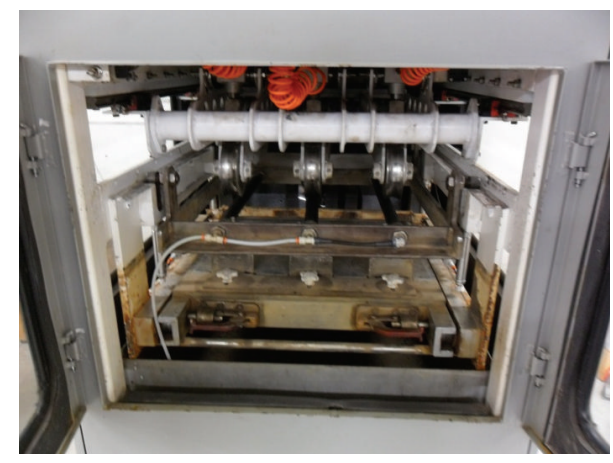

(b) APA rutting test

FIGURE 3: Laboratory test apparatuses of asphalt mixture: (a) dynamic modulus and (b) APA rutting.

the control asphalt, and the MCF materials are well dispersed in the asphalt matrix. The tube carbon fibers are filled as support in the asphalt and may also enhance the interaction and adhesion strengths within the asphalt. It is likely that the ribbing structures of micro carbon fibers in asphalt help prevent cracking failure under low temperatures, similar to reinforcing steel in concrete. These effects may lead to an increase in dynamic modulus and an improvement in the resistance to permanent deformation of modified asphalt mixtures.

Figure 4(b) demonstrates the dynamic modulus data trends of Nanomer modified and control asphalt mixtures at different contents. The addition of Nanomer material at different amounts in the asphalt mixture raises the dynamic modulus. The dynamic moduli of $2 \%$ and $4 \%$ Nanomer modified asphalt mixtures increase by an average of $30 \%$ and $25 \%$, respectively. The high-temperature dynamic modulus of $4 \%$ Nanomer modified asphalt mixtures tends to be mildly greater than that of the $2 \%$ Nanomer modified asphalt mixture. However, when under low temperatures, it is lower than that of the $2 \%$ Nanomer modified asphalt mixture. It is likely that the $4 \%$ Nanomer modified asphalt concrete is stiffer than the $2 \%$ Nanomer modified asphalt concrete at high temperatures. On the contrary, under low temperatures, it is softer than the $2 \%$ Nanomer modified asphalt concrete. The rutting resistance and temperature susceptibility of the Nanomer modified asphalt mixture ameliorate relative to the control asphalt mixture. The improvement in the dynamic modulus of the Nanomer modified asphalt mixture is due to the changes in microstructure of the Nanomer modified asphalt binder in contrast with the control asphalt. As seen in the SEM image of Figure 7(b), the layer structure of the Nanomer was intercalated/exfoliated by the asphalt binder after the addition of Nanomer materials into the asphalt binder. Some Nanomer granules were physically decentralized in the asphalt matrix. A variation in microstructure and chemical reactions in the Nanomer modified asphalt binder might occur relative to the control asphalt binder [15]. The circuitous and expanded "brain" structures in the Nanomer asphalt bring in additional adhesive/cohesive bonds to the aggregates. The granules of Nanomer materials may fill the gap between the aggregates. These phenomena in the modified asphalt induce the improvement in the dynamic modulus in asphalt mixtures, as well as the susceptibility to rutting.
Figure 4(c) displays the dynamic modulus data tendencies of nanosilica modified and control asphalt mixtures at different contents. The addition of NS material into the control asphalt mixture leads to an improvement in the dynamic modulus of NS modified asphalt mixtures. The dynamic moduli of $4 \%$ and $6 \%$ NS modified asphalt mixtures rise by an average of $30 \%$ and $28 \%$, respectively. The $6 \%$ NS modified asphalt mixture has a higher high-temperature modulus than the $4 \%$ NS modified asphalt mixture from the trend in the modulus. However, it has lower low-temperature moduli than the $4 \%$ NS modified asphalt mixture. It is possible that the $6 \%$ NS in the modified asphalt mixture may produce a better performance of high-temperature rutting resistance and lowtemperature creep compliance than the $4 \%$ NS material in the modified asphalt mixture. From the dynamic modulus data trends, it is likely that the high-temperature performance of the NS modified asphalt mixture was enhanced in contrast to the control asphalt mixture. As shown in Figure 7(c), some nanosilica granules were scattered in the asphalt matrix. Due to the existence of ABS (silane coupling agent) in the control asphalt and hydroxyl in the nanoparticles, the surfaces of nanosilica materials are converted from hydrophilic to hydrophobic [31-34]. Contrary to the control asphalt, it is possible that the tree or leaf stem structures of NS modified asphalt produce more contact forces with the aggregates and physically scattered nanoparticles fill the separations between the aggregates. These special structures increase the strength of adhesion in asphalt binders and asphalt mixtures. Therefore, the physical dispersions and chemical reactions between the nanosilica and asphalt binder lead to amelioration of the dynamic modulus of the NS modified asphalt concrete.

Figure 4(d) reveals the dynamic modulus master curves of NMN modified and control asphalt mixtures at different amounts. The control asphalt mixture has smaller dynamic moduli than the NMN modified mixture. The addition of NMN material into the control asphalt mixture increases dynamic moduli around $15 \%$. The moduli of NMN modified asphalt mixtures at different contents are similar in magnitude. It is noted that the dynamic moduli of the $4 \%$ NMN modified mixture are relatively higher than those of the $2 \%$ NMN modified mixture under low frequencies and high temperatures, but moduli of the $4 \%$ NMN modified mixture are lower than those of the $2 \%$ NMN modified 


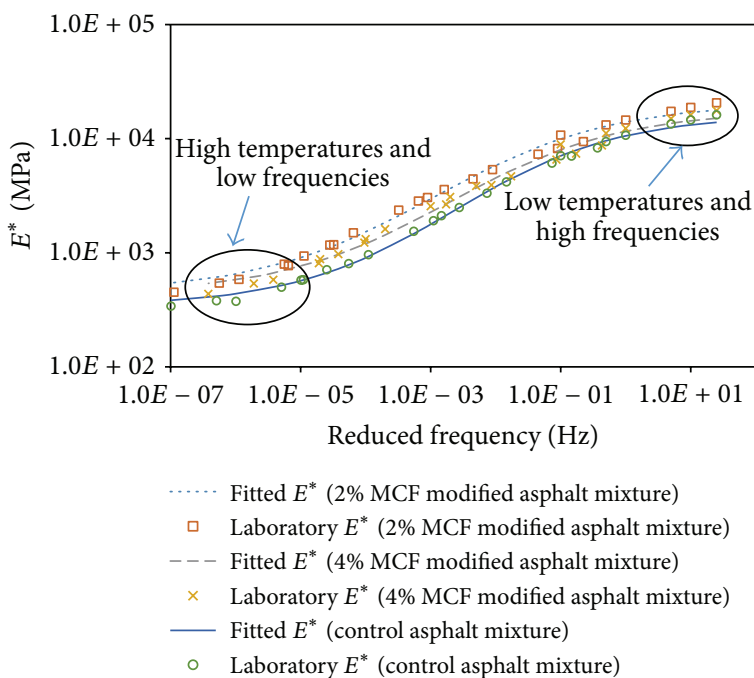

(a)

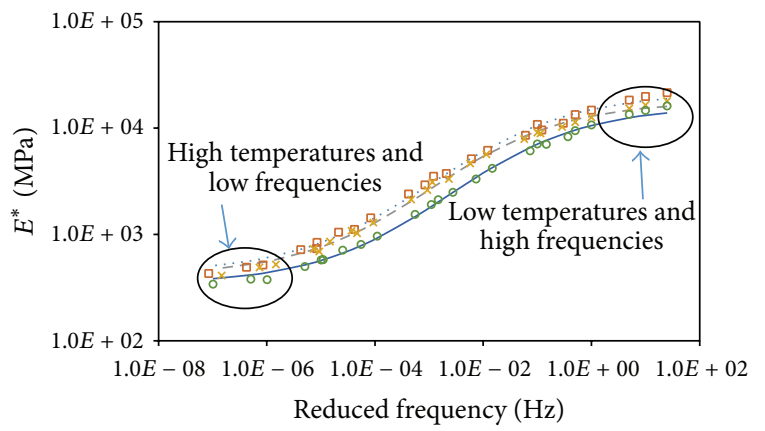

Fitted $E^{*}$ ( $4 \%$ NS modified asphalt mixture)

$\square \quad$ Laboratory $E^{*}$ (4\% NS modified asphalt mixture)

- - - Fitted $E^{*}$ (6\% NS modified asphalt mixture)

$\times \quad$ Laboratory $E^{*}$ ( $6 \%$ NS modified asphalt mixture)

- Fitted $E^{*}$ (control asphalt mixture)

- Laboratory $E^{*}$ (control asphalt mixture)

(c)

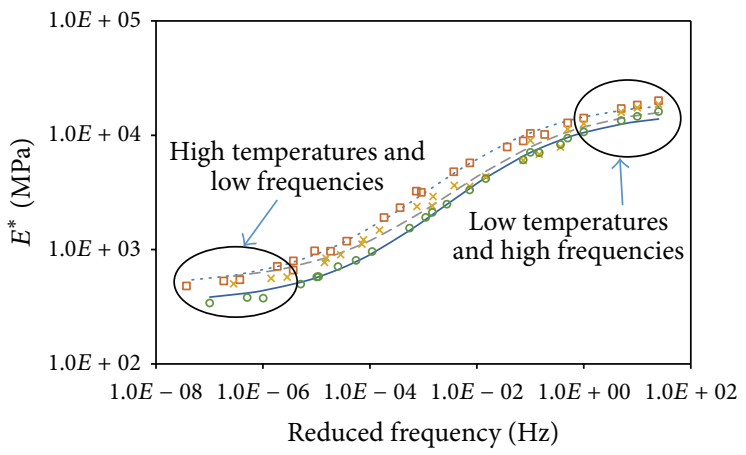

Fitted $E^{*}(2 \%$ Nanomer modified asphalt mixture)

口 Laboratory $E^{*}$ ( $2 \%$ Nanomer modified asphalt mixture)

- - Fitted $E^{*}$ (4\% Nanomer modified asphalt mixture)

$\times \quad$ Laboratory $E^{*}(4 \%$ Nanomer modified asphalt mixture)

- Fitted $E^{*}$ (control asphalt mixture)

- Laboratory $E^{*}$ (control asphalt mixture)

(b)

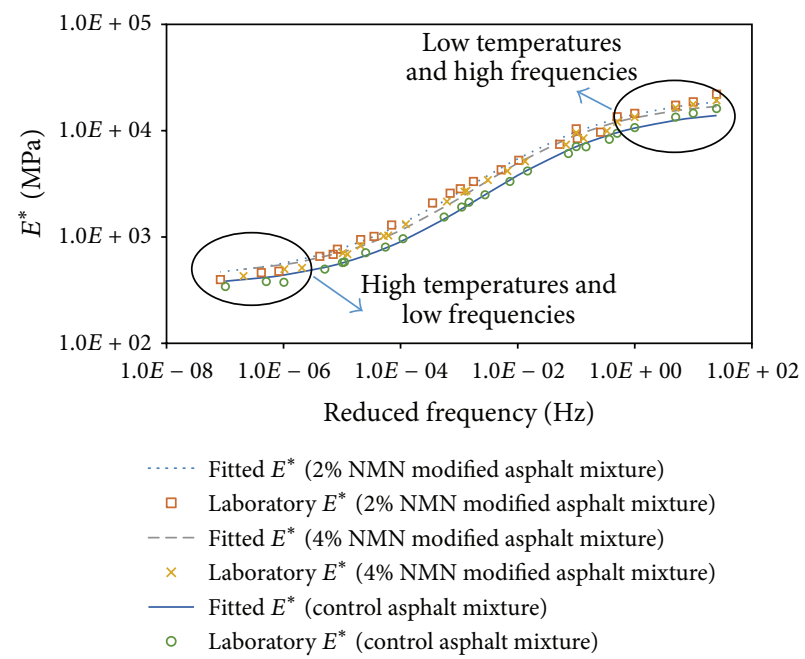

(d)

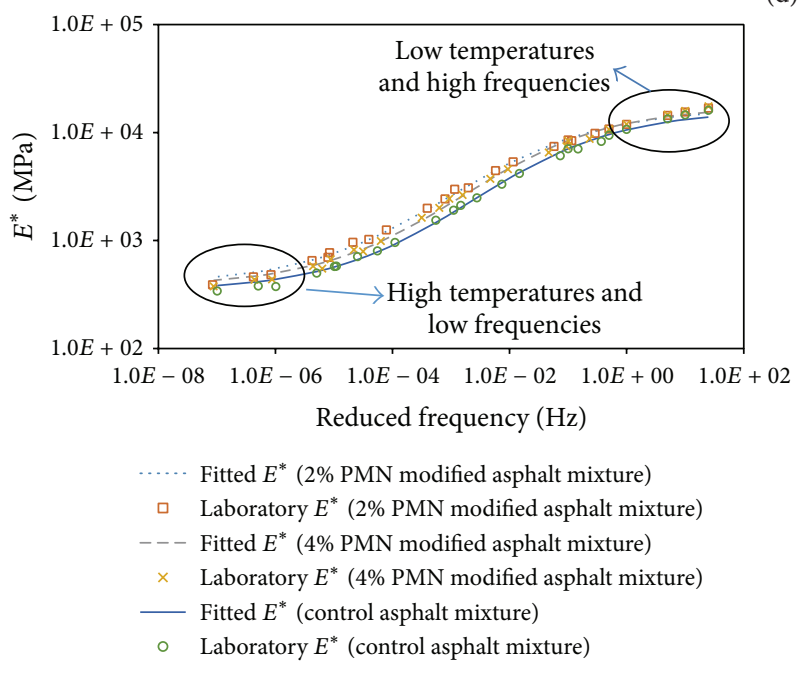

(e)

Figure 4: Dynamic modulus results of micro-, nanomodified and control asphalt mixtures. (a) Dynamic modulus $E^{*}$ results and master curves (MC) of carbon microfiber modified and control asphalt mixtures (reference temperature: $-10^{\circ} \mathrm{C}$ ). (b) Dynamic modulus $E^{*}$ results and master curves $(\mathrm{MC})$ of Nanomer modified and control asphalt mixtures (reference temperature: $-10^{\circ} \mathrm{C}$ ). (c) Dynamic modulus $E^{*}$ results and master curves (MC) of nanosilica modified and control asphalt mixtures [20] (reference temperature: $-10^{\circ} \mathrm{C}$ ). (d) Dynamic modulus master curves (MC) of NMN modified and control asphalt mixtures (reference temperature: $-10^{\circ} \mathrm{C}$ ). (e) Dynamic modulus master curves $(\mathrm{MC})$ of PMN modified and control asphalt mixtures (reference temperature: $-10^{\circ} \mathrm{C}$ ). 


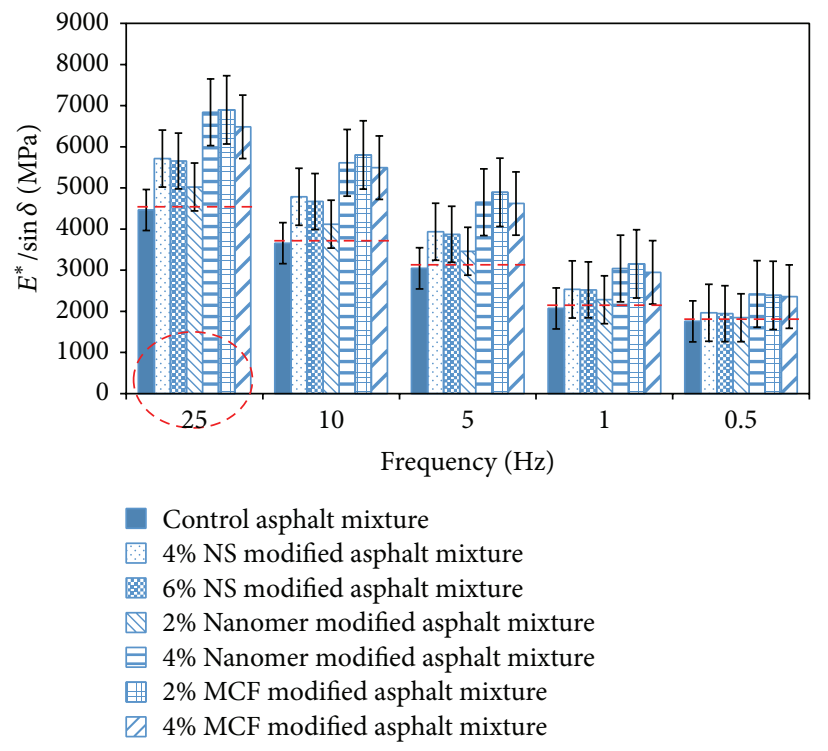

(a)

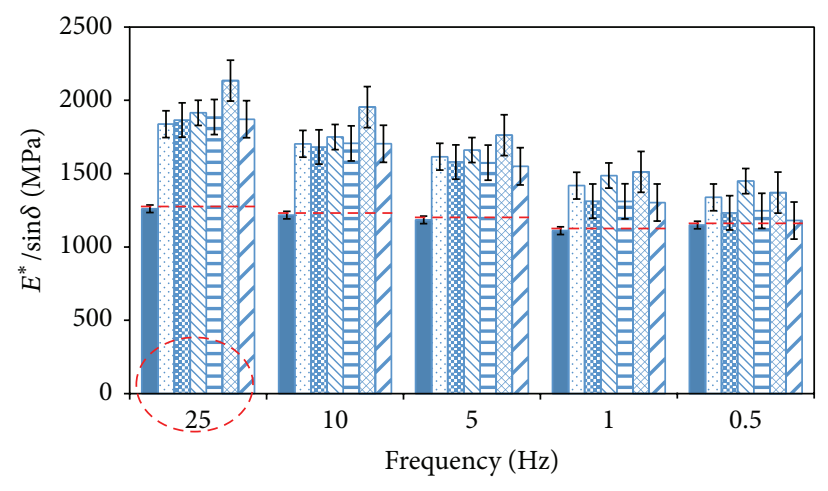

Control asphalt mixture

$4 \%$ NS modified asphalt mixture

6\% NS modified asphalt mixture

$2 \%$ Nanomer modified asphalt mixture

曰 $4 \%$ Nanomer modified asphalt mixture

$2 \%$ MCF modified asphalt mixture

$\triangle 4 \%$ MCF modified asphalt mixture

(b)

Figure 5: $E^{*} / \sin \delta$ results of modified and control asphalt mixtures. (a) $E^{*} / \sin \delta$ results of mixtures at $21.3^{\circ} \mathrm{C}$ (left-to-right of one set: control asphalt mixture, $4 \%$ NS modified asphalt mixture, $6 \%$ NS modified asphalt mixture, $2 \%$ Nanomer modified asphalt mixture, $4 \%$ Nanomer modified asphalt mixture, $2 \%$ MCF modified asphalt mixture, and 4\% MCF modified asphalt mixture). (b) $E^{*} / \sin \delta$ results of mixtures at $39.2^{\circ} \mathrm{C}$ (left-to-right of one set: control asphalt mixture, $4 \% \mathrm{NS}$ modified asphalt mixture, $6 \%$ NS modified asphalt mixture, $2 \%$ Nanomer modified asphalt mixture, $4 \%$ nanomer modified asphalt mixture, $2 \%$ MCF modified asphalt mixture, and $4 \%$ MCF modified asphalt mixture).

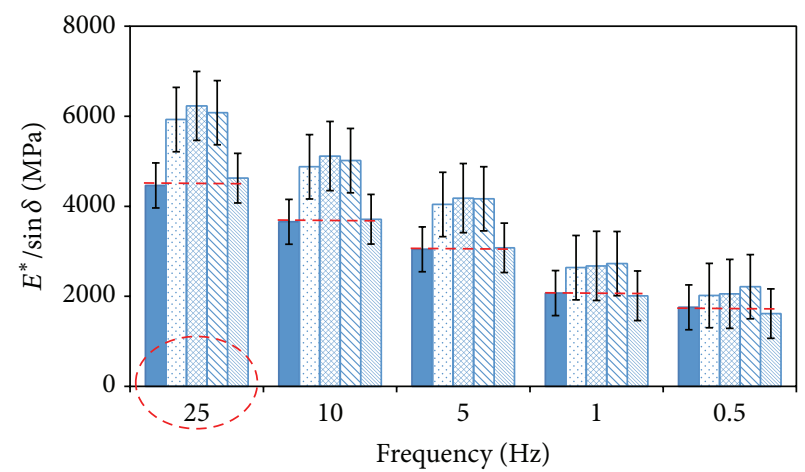

Control asphalt mixture

$2 \%$ NMN modified asphalt mixture

$4 \%$ NMN modified asphalt mixture

2\% PMN modified asphalt mixture

$4 \%$ PMN modified asphalt mixture

(a)

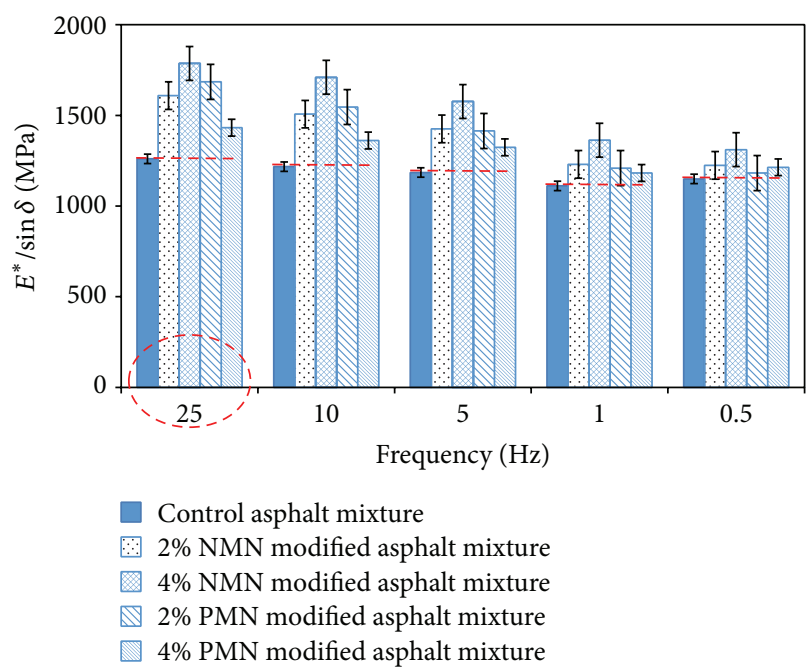

(b)

FIGURE 6: $E^{*} / \sin \delta$ comparisons of nanomodified and control asphalt mixtures. (a) $E^{*} / \sin \delta$ results of mixtures at $21.3^{\circ} \mathrm{C}$ (left-to-right of one set: control asphalt mixture, $2 \% \mathrm{NMN}$ modified asphalt mixture, $4 \% \mathrm{NMN}$ modified asphalt mixture, $2 \%$ PMN modified asphalt mixture, and $4 \% \mathrm{PMN}$ modified asphalt mixture). (b) $E^{*} / \sin \delta$ results of mixtures at $39.2^{\circ} \mathrm{C}$ (left-to-right of one set: control asphalt mixture, $2 \% \mathrm{NMN}$ modified asphalt mixture, 4\% NMN modified asphalt mixture, 2\% PMN modified asphalt mixture, and 4\% PMN modified asphalt mixture).

mixture under high frequencies and low temperatures. A low modulus of asphalt mixtures at low temperatures relates to a positive effect on the resistance to low-temperature cracking of asphalt mixtures [35]. This indicates that the $4 \%$ NMN modified mixture is relatively stiffer under high temperatures and softer under low temperatures than the $2 \%$ NMN modified mixture. It is likely that the $4 \%$ NMN modified asphalt mixture has a superior performance of a high-temperature rutting resistance and a better lowtemperature creep compliance over the $2 \%$ NMN modified and control asphalt mixtures. The wrinkly structure of NMN modified asphalt contributes to the increase in adhesive and cohesive energies between the asphalt and aggregate relative to the structure of the control asphalt (Figure 7(d)). 


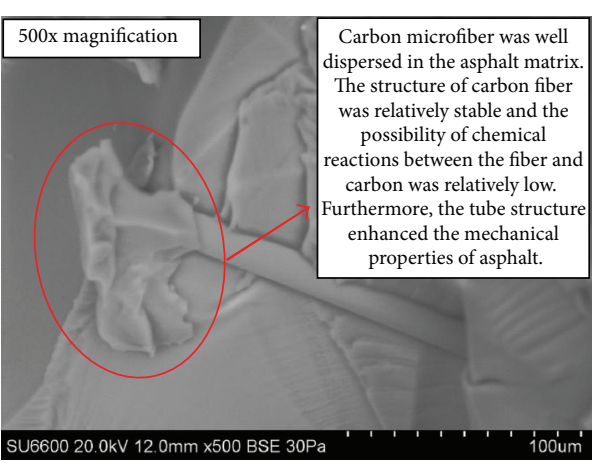

(a) SEM/microstructure image of $2 \%$ MCF modified asphalt

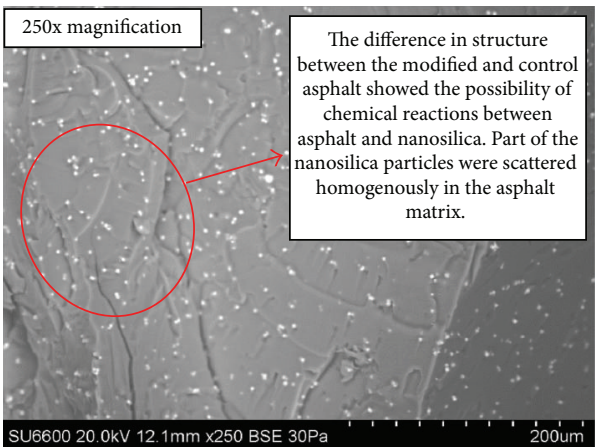

(c) SEM/microstructure image of $6 \%$ NS modified asphalt

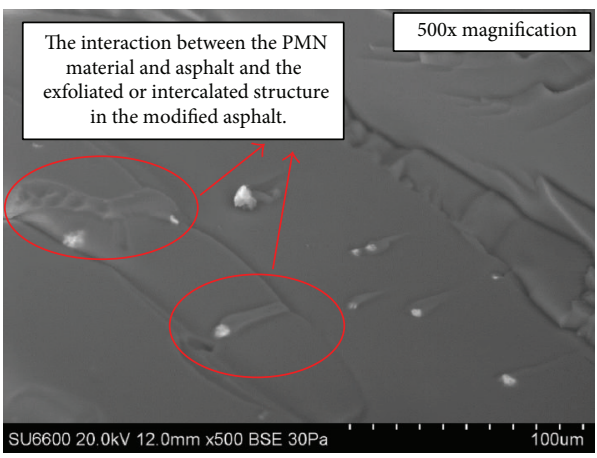

(e) SEM/microstructure image of $2 \%$ PMN modified asphalt

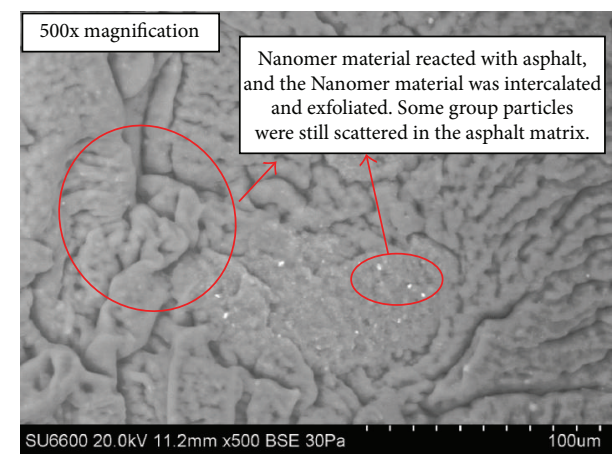

(b) SEM/microstructure image of $2 \%$ Nanomer modified asphalt

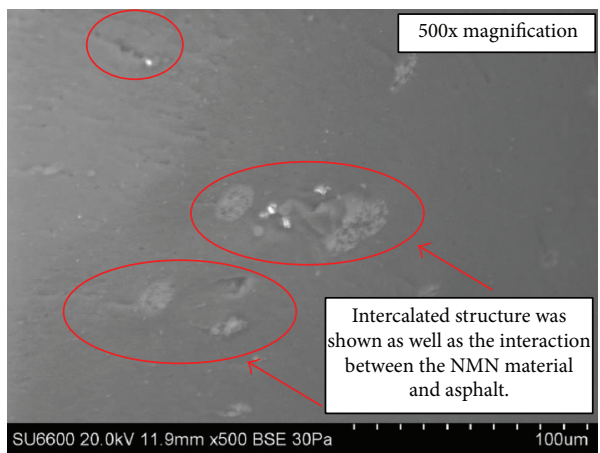

(d) SEM/microstructure image of $2 \%$ NMN modified asphalt

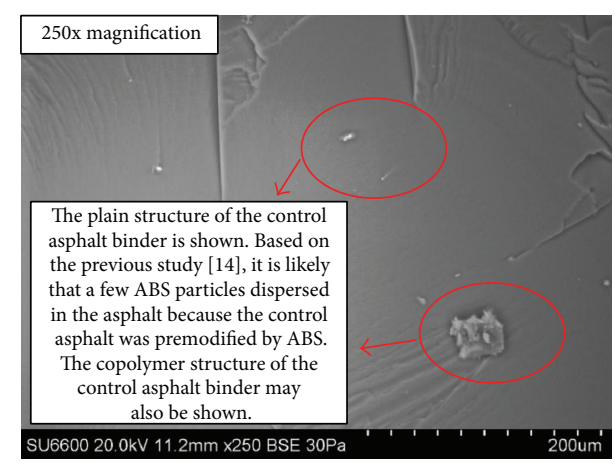

(f) SEM/microstructure image of control asphalt

FIGURE 7: SEM images of control, micro-, and nanomodified asphalt binders.

The physically scattered NMN material in the structure of NMN modified asphalt may fill in the holes of aggregates and can be helpful for the dense structure formation in the asphalt mixture from the microstructure views. Therefore, NMN material in the asphalt mixture may improve the mechanical and pavement performance.

Figure 4(e) demonstrates the dynamic modulus data of the PMN modified and control asphalt mixtures. The PMN modified mixture presents a high dynamic modulus in contrast to the control asphalt mixture. The PMN material in the control asphalt mixture increases the dynamic modulus by $10 \%$. The moduli of the $4 \%$ PMN modified mixture are relatively lower than the $2 \%$ PMN modified mixture under low temperatures and high frequencies. It is likely that the $4 \%$ PMN material in the control mixture presents a better performance of low-temperature and fatigue cracking resistance than the $2 \% \mathrm{PMN}$ in the asphalt mixture. Due to the exfoliation of PMN in the polymer [15], the folder zone in the PMN modified asphalt may be useful to adhere to the aggregates (Figure 7(e)). The overlay structure increases the surface area of asphalt relative to the control asphalt and may enhance the interaction forces between the asphalt and aggregates. Therefore, PMN material in the asphalt mixture may be useful for the rutting resistance.

Figure 5 shows the $E^{*} / \sin \delta$ (rut factor) values of the control, NS, MCF, and Nanomer modified asphalt mixtures at 
TABLE 1: ANOVA results of modifying effects of micro- and nanomaterials on $E^{*}$.

\begin{tabular}{|c|c|c|c|c|c|c|}
\hline Source & SS & $\mathrm{df}$ & MS & F & $P$-value & $F_{\text {crit }}$ \\
\hline C VS 1 & $2.68 E+08$ & $1.00 E+00$ & $2.68 E+08$ & $2.15 E+01$ & $2.92 E-05$ & $4.05 E+00$ \\
\hline C VS 2 & $2.28 E+06$ & $1.00 E+00$ & $2.28 E+06$ & $8.98 E-02$ & $7.66 E-01$ & $4.05 E+00$ \\
\hline C VS 3 & $4.28 E+07$ & $1.00 E+00$ & $4.28 E+07$ & $1.21 E+00$ & $2.76 E-01$ & $4.05 E+00$ \\
\hline C VS 4 & $2.73 E+07$ & $1.00 E+00$ & $2.73 E+07$ & $8.24 E-01$ & $3.69 E-01$ & $4.05 E+00$ \\
\hline C VS 5 & $2.46 E+07$ & $1.00 E+00$ & $2.46 E+07$ & $7.51 E-01$ & $3.91 E-01$ & $4.05 E+00$ \\
\hline
\end{tabular}

Note: SS: sum of squares; df: degree of freedom; MS: mean squares; $F: F$ value; $F_{\text {crit }}$ : the critical value of $F$; the significance level is $0.05 ; C$ : control; $1: 2 \%$ NMN; 2: 2\% PMN; 3: 4\% NS; 4: 2\% MCF; 5: 2\% Nanomer.

$21.3^{\circ} \mathrm{C}$ and $39.2^{\circ} \mathrm{C}$. The $E^{*} / \sin \delta$ values of these modified mixtures are relatively greater than the control mixture at high temperatures and different frequencies. This indicates that the resistance to rutting of these modified mixtures should be enhanced in contrast to the control mixture. There is an agreement between the outcomes of the dynamic modulus and rut factor of these modified asphalt mixtures. Figure 6 shows the $E^{*} / \sin \delta$ results of the NMN and PMN modified and control mixtures. The nanomodified asphalt mixtures present high $E^{*} / \sin \delta$ values in contrast to the control asphalt mixtures. The high $E^{*} / \sin \delta$ asphalt mixture corresponds to a good resistance to rutting. These findings coincide with the modulus results of NMN and PMN modified and control mixtures. Seen from the microstructure images of asphalt in Figure 7, the microstructures of micro- and nanomodified asphalt are significantly different from the control asphalt. The surface areas of these modified asphalt binders increase, and this may induce the growth of adhesion energy between the asphalt and aggregates. Based on the literature review $[15,19,20,23,24]$, it is likely that the NMN, PMN, nanosilica, and Nanomer materials react with the asphalt. The addition of NMN, PMN, and Nanomer materials in asphalt leads to the formation of intercalated or exfoliated layer structures in the modified asphalt. However, there is a small probability that the MCF material can chemically react with asphalt. The microstructure property of asphalt definitely relates to the macroscopic performance of the asphalt mixture. The high dynamic modulus and $E^{*} / \sin \delta$ values of these modified asphalt mixtures benefit from the new microstructures of the asphalt binders. Therefore, with regard to the rut factors, the micro- and nanomaterials in asphalt mixtures may improve the resistance to rutting in most cases.

5.2. ANOVA Analysis on $E^{*}$. Micro- and nanomaterials in the asphalt mixtures can improve the dynamic modulus and rutting factors of modified mixtures. In order to evaluate the modifying effects of micro- and nanomaterials on the dynamic modulus of the asphalt mixtures, ANOVA was selected and conducted using the Excel program with a single factor [36]. The analysis data of the dynamic modulus was tested under the different temperatures and frequencies (Section 5.1). In the ANOVA $F$-test, the significance level $(\alpha)$ was 0.05 (default value) or the $95 \%$ confidence interval was used in this study. Table 1 shows the ANOVA results of the modification effects of micro- and nanomaterials on the dynamic
TABLE 2: ANOVA results of the dynamic modulus $E^{*}$ of the microand nanomodified asphalt mixtures.

\begin{tabular}{lcccccc}
\hline \multirow{2}{*}{ Source } & \multicolumn{6}{c}{ Influence level (control and modified asphalt mixtures) } \\
& $\mathrm{C}$ & 1 & 2 & 3 & 4 & 5 \\
\hline $\mathrm{C}$ & - & $\mathrm{S}$ & $\mathrm{N}$ & $\mathrm{N}$ & $\mathrm{N}$ & $\mathrm{N}$ \\
1 & & - & $\mathrm{S}$ & $\mathrm{S}$ & $\mathrm{S}$ & $\mathrm{S}$ \\
2 & & & - & $\mathrm{N}$ & $\mathrm{N}$ & $\mathrm{N}$ \\
3 & & & & - & $\mathrm{N}$ & $\mathrm{N}$ \\
4 & & & & & - & $\mathrm{N}$ \\
5 & & & & & & - \\
\hline
\end{tabular}

Note: the significance level is 0.05; C: control; 1: 2\% NMN; 2: 2\% PMN; 3: 4\% NS; 4: 2\% MCF; 5: 2\% Nanomer; N: nonsignificant; S: significant.

modulus $E^{*}$ of the control mixture. The effects of temperature and frequency on $E^{*}$ were ignored in the one-way ANOVA analysis. It can be seen that the materials have different levels of influence in all cases. In Table 1 , the $P$ value is much less than 0.05 and the $F$ value is significantly higher than $F_{\text {crit }}$ in the case: "C VS 1." This indicates that the NMN material has a significant effect on the improvement of the dynamic modulus in asphalt mixtures. The other materials (PMN, NS, MCF, and Nanomer) can improve the dynamic modulus, but these materials do not have a significant influence on the dynamic modulus from the statistical analysis.

Table 2 demonstrates the ANOVA data of the dynamic modulus between two random asphalt mixtures. The effects of improvement of the dynamic modulus between two random groups were analyzed using one-way ANOVA. The NMN material still has a remarkable influence on the dynamic modulus in contrast to the other materials. The level of influence between the other two materials is not prominent.

5.3. APA Rutting Test Results. The APA is a kind of accelerated laboratory rutting test, and it is used to measure the potential for rut on the asphalt mixtures. The conditions of load, the cycle number of wheeling, and temperature are important for consistent testing and accurate results in the field performance [25]. The setting parameters were mentioned in the section discussing the mixture test plan. The results of the APA tests were processed through the moving average of the statistical analysis so that the trend of data was shown clearly. The moving average is a method of data 


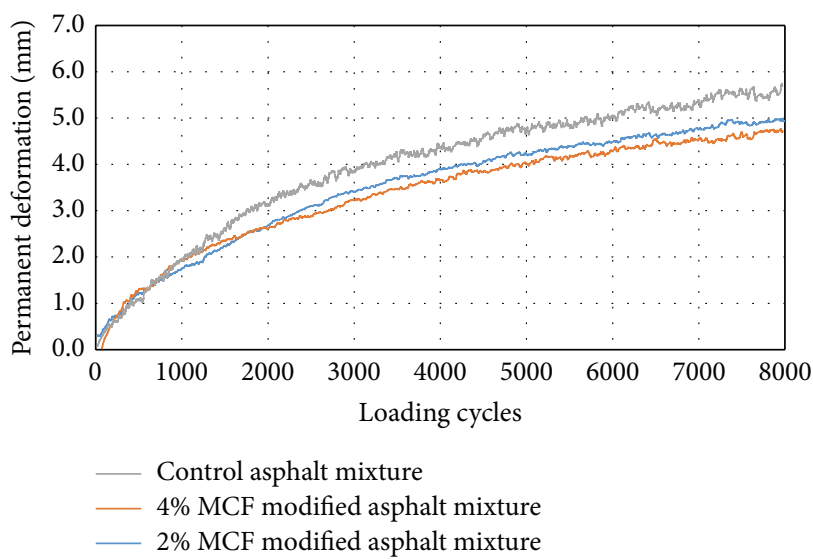

(a)

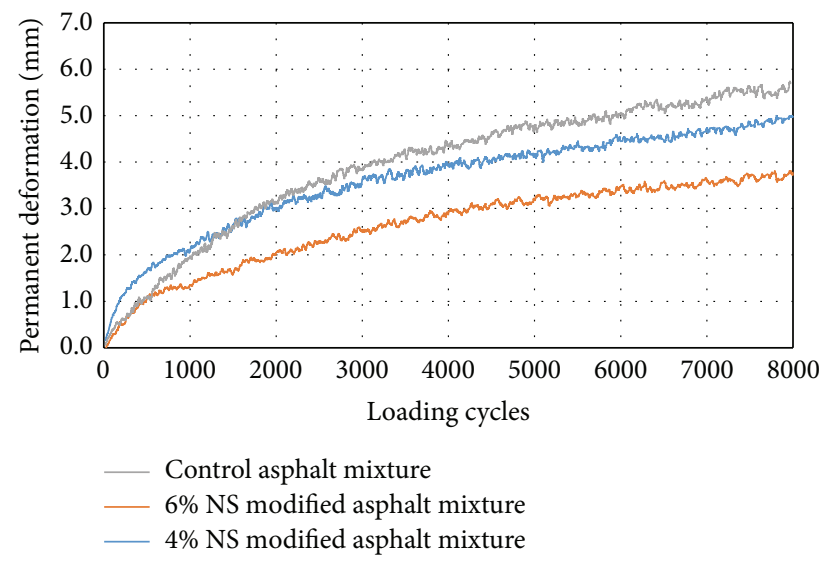

(c)

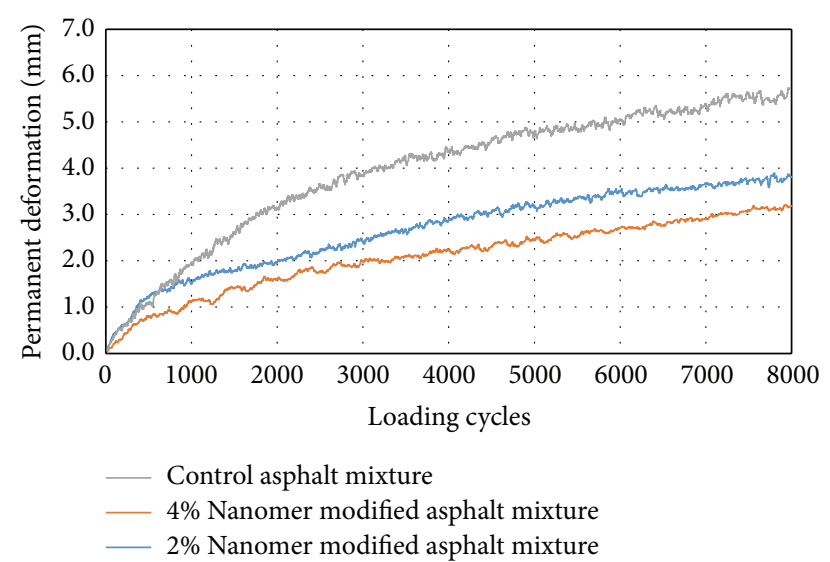

(b)

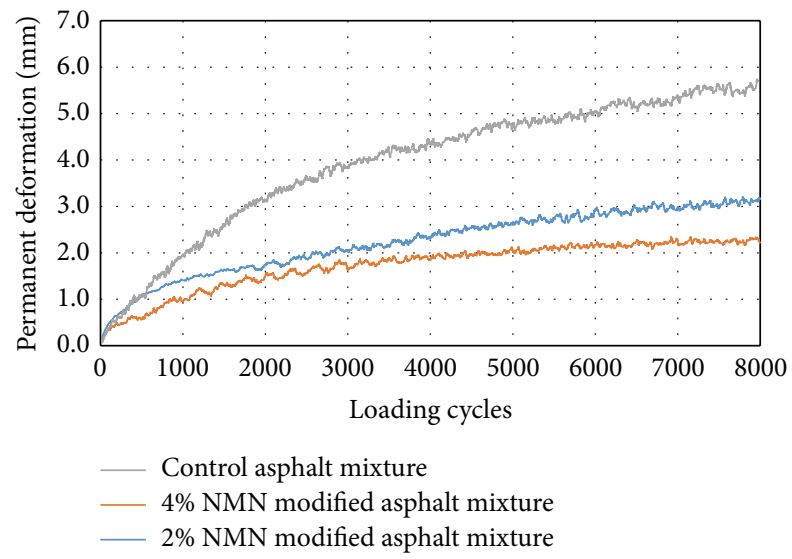

(d)

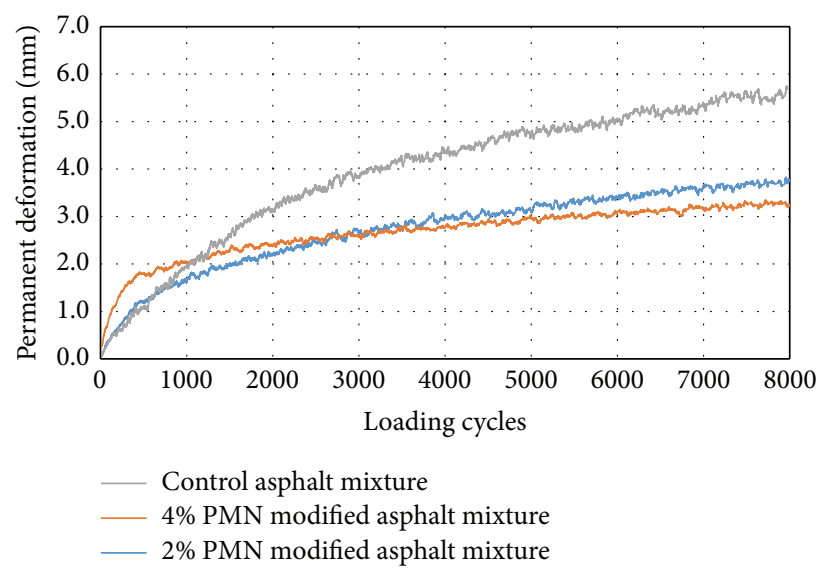

(e)

FigURE 8: Rut depth data of micro-, nanomodified, and control asphalt mixtures. (a) Rut depth data of carbon microfiber modified and control asphalt mixtures (moving average). (b) Rut depth data of Nanomer modified and control asphalt mixtures (moving average). (c) Rut depth data of nanosilica modified and control asphalt mixtures [20] (moving average). (d) Rut depth data of NMN modified and control asphalt mixtures (moving average). (e) Rut depth data of PMN modified and control asphalt mixtures (moving average).

processing to create a series of average data in the full data set. The simple moving average (SMA) [37] is an unweighted mean of selected data and the equation of $n$ data samples is shown in (2). The average of 20 data points (period setting) was used in the statistical analysis. The APA rut depth results of micro- and nanomodified asphalt mixtures are shown in Figure 8:

$$
\mathrm{SMA}=\frac{p_{M}+p_{M-1}+\cdots+p_{M-(n-1)}}{n} .
$$


Figure 8(a) shows the rut depth data of MCF modified and control asphalt mixtures at the temperature of $58^{\circ} \mathrm{C}$. A lower rut depth in the MCF modified asphalt mixture is presented relative to the control asphalt mixture. However, the rut depths of the $2 \% \mathrm{MCF}$ modified asphalt mixture are greater than those of the $4 \%$ MCF modified asphalt mixture. The rut depths of the $2 \%$ and $4 \%$ MCF modified asphalt mixture decrease by around $15 \%$ and $20 \%$, respectively, in contrast to the control asphalt mixture. This indicates that the high percentages of MCF in the asphalt mixture result in low rutting depths in the modified asphalt mixtures during the APA test. Therefore, the rut susceptibility of the MCF modified asphalt mixture is reduced. The APA rut depth data of the MCF modified asphalt mixtures coincides with the rut factor $E^{*} / \sin \delta$ and dynamic modulus results. The tube MCFs are homogenously decentralized in the asphalt matrix because they are relatively stable in the natural environment (Figure 7(a)). The MCFs may increase the strength of adhesion between asphalt and aggregate and may also improve the resistance to permanent deformation in asphalt mixtures due to the high strength of MCFs. It is likely that the microfiber bridges the aggregates and prevents cracking in the asphalt mixtures on the micro scale.

Figure 8(b) displays the APA rut data of Nanomer modified and control asphalt mixtures at a temperature of $58^{\circ} \mathrm{C}$. The testing rut data of Nanomer modified asphalt mixtures is lower than that of the control asphalt mixture, but the testing rut data of the $2 \%$ Nanomer modified asphalt mixture is higher than that of the asphalt mixture with $4 \%$ Nanomer. The addition of $2 \%$ and $4 \%$ Nanomer materials into the asphalt mixture decreases the testing depths by an average of $30 \%$ and $40 \%$, respectively. The large percentage of Nanomer material in the asphalt mixture may cause the reduction in rutting depths in the modified mixture. Therefore, Nanomer material in the asphalt mixture can improve the rutting resistance of the modified mixture. The APA rut depth results of Nanomer modified asphalt mixtures stay consistent with their dynamic modulus and $E^{*} / \sin \delta$ results. It is likely that the resistance of the modified asphalt mixtures to permanent deformation is ameliorated due to the "circuitous and expanded brain" structure in the Nanomer modified asphalt (Figure 7(b)). In Figure 7(b), it is apparent that the chemical reactions and physical dispersions between the Nanomer material and asphalt occur relative to the base asphalt. This special structure in the Nanomer modified asphalt helps to adhere asphalt to the aggregates, as well as to strongly and fully coat the aggregates.

Figure $8(\mathrm{c})$ shows the APA rutting data of nanosilica modified and control asphalt mixtures at a temperature of $58^{\circ} \mathrm{C}$. The testing rut depths of the control asphalt mixture are greater than those of the asphalt mixtures with the nanosilica material, and the testing rut data of the asphalt mixture with $6 \%$ nanosilica is lower than that of the $4 \%$ NS modified asphalt mixture. A content of $4 \%$ or $6 \%$ NS in the control asphalt mixture can decrease the rut depths in the modified mixtures by an average of $15 \%$ and $30 \%$, respectively. It is likely that the higher concentration of NS in the asphalt mixture may result in lower rut depths in the modified asphalt mixtures. Physical dispersions and chemical reactions in the nanosilica took place in the asphalt matrix, and the "tree or leaf" structure in the modified asphalt was formed (Figure 7(c)). Synthesizing the results of the performance tests, it is apparent that the improvement of rutting resistance in the modified asphalt mixture benefits from these skeleton structures. In addition, it is probable that the hydrophilic state change on the surface of nanosilica helps improve the performance.

Figure $8(\mathrm{~d})$ displays the APA rutting data of the NMN modified and control asphalt mixtures at the temperature of $58^{\circ} \mathrm{C}$. The control asphalt mixture has higher rut depths than both NMN modified asphalt mixtures during the loading cycles, and the permanent deformation of the asphalt mixture with $2 \%$ NMN material is higher than the asphalt mixture with $4 \% \mathrm{NMN}$. The rut depths of the asphalt mixture with $4 \%$ NMN material decrease by around $110 \%$ in contrast to the control mixture. Meanwhile, seen from the data trend in Figure 4(d), it is possible that the higher percentages of NMN material in the control asphalt mixture cause lower rut depths in the modified mixture. NMN material in the asphalt mixture improves the rutting resistance of the modified mixture significantly. The APA rutting data of the asphalt mixture coincides with the $E^{*} / \sin \delta$ and dynamic modulus results. The improvement in the resistance to permanent deformation may be due to the increase in strength between the asphalt and aggregates. Meanwhile, the strength of adhesion between the NMN modified asphalt and aggregates may increase due to cation exchanges (Figure 7(d)) in the NMN modified asphalt. The structure of NMN is intercalated with the polymer (asphalt) and leads to the formation of the wrinkled structure in the modified asphalt. Some NMN particles are still dispersed in the asphalt due to the agglomeration of nanomaterials. The microstructure of asphalt potentially affects the macroscopic performance of asphalt mixtures. The NMN modified asphalt mixture becomes stiffer at high temperatures and can resist more loads relative to the control mixture.

Figure 8(e) reveals the rutting test results of the PMN modified and control asphalt mixtures at a temperature of $58^{\circ} \mathrm{C}$. The control asphalt mixture has a higher permanent deformation than both PMN modified asphalt mixtures during the loading cycles. The rut depths of the asphalt mixture with $2 \%$ PMN are greater than those of the asphalt mixture with 4\% PMN, but the difference between the asphalt mixtures with $2 \%$ and $4 \%$ PMN materials is not significant. The rut depths of the asphalt mixture with 4\% PMN decrease by around $70 \%$ compared to the control mixture. It is likely that a higher percentage of PMN added to the control asphalt mixture may result in less permanent deformation of the PMN modified mixture. Therefore, PMN material in the asphalt mixture shows a positive effect on the rutting resistance of the modified mixture. The rut depth data of the control and the asphalt mixture with PMN material coincides with the $E^{*} / \sin \delta$ and dynamic modulus results. The effective amelioration of the rutting resistance in the modified mixture may be due to the fact that the structure of the layers of PMN is easy to exfoliate and intercalate with the polymer (asphalt) (Figure 7(e)). The "stair framework and fold zone" in the PMN modified asphalt are formed after the physical scatter and chemical reaction. The adhesive/cohesive 
TABLE 3: ANOVA results of modifying effects of micro- and nanomaterials on rut depths.

\begin{tabular}{|c|c|c|c|c|c|c|}
\hline Source & SS & $\mathrm{df}$ & MS & $F$ & $P$-value & $F_{\text {crit }}$ \\
\hline C VS 1 & $1.49 E+04$ & $1.00 E+00$ & $1.49 E+04$ & $1.19 E+04$ & $0.00 E+00$ & $3.84 E+00$ \\
\hline C VS 2 & $4.63 E+03$ & $1.00 E+00$ & $4.63 E+03$ & $3.69 E+03$ & $0.00 E+00$ & $3.84 E+00$ \\
\hline C VS 3 & $5.27 E+03$ & $1.00 E+00$ & $5.27 E+03$ & $3.40 E+03$ & $0.00 E+00$ & $3.84 E+00$ \\
\hline C VS 4 & $1.04 E+03$ & $1.00 E+00$ & $1.04 E+03$ & $5.81 E+02$ & $1.05 E-125$ & $3.84 E+00$ \\
\hline C VS 5 & $1.07 E+04$ & $1.00 E+00$ & $1.07 E+04$ & $7.63 E+03$ & $0.00 E+00$ & $3.84 E+00$ \\
\hline
\end{tabular}

Note: SS: sum of squares; df: degree of freedom; MS: mean squares; $F: F$ value; $F_{\text {crit }}$ : the critical value of $F$; the significance level is 0.05 ; C: control; $1: 4 \%$ NMN; 2: 4\% PMN; 3: 6\% NS; 4: 4\% MCF; 5: 4\% Nanomer.

TABLE 4: ANOVA results of the rut depths of the micro- and nanomodified asphalt mixtures.

\begin{tabular}{lcccccc}
\hline \multirow{2}{*}{ Source } & \multicolumn{6}{c}{ Influence level (control and modified asphalt mixtures) } \\
& C & 1 & 2 & 3 & 4 & 5 \\
\hline C & - & S & S & S & S & S \\
1 & & - & S & S & S & S \\
2 & & & - & S & S & S \\
3 & & & & - & S & S \\
4 & & & & & - & S \\
5 & & & & & & -
\end{tabular}

Note: the significance level is 0.05; C: control; 1: 4\% NMN; 2: 4\% PMN; 3: 6\% NS; 4: 4\% MCF; 5: 4\% Nanomer; N: nonsignificant; S: significant.

strengths between the PMN modified asphalt and aggregates increase. During the loading cycles, the asphalt mixture with the PMN material becomes harder in contrast to the control mixture and can support more loads at high temperatures.

5.4. ANOVA Analysis on Rut Depths. From the APA rutting test results, the micro- and nanomaterials in the asphalt mixtures can reduce the rut depths of the modified mixtures. The statistical significance of rut depths in asphalt mixtures at $58^{\circ} \mathrm{C}$ was examined using one-way ANOVA in order to analyze the modifying effect of micro- and nanomaterials on the rutting resistance of the asphalt mixtures. The ANOVA test was operated by the Excel program and the significance level was 0.05 . Table 3 displays the ANOVA data of the modified effects of micro- and nanomaterials on the rut depths in these modified mixtures. It is noticed that the $P$ values are all generally less than the default significance level in all cases and the $F$ values are highly larger than $F_{\text {crit }}$. This implies that these materials have significant effects on ameliorating the rutting resistance of the asphalt mixtures.

Table 4 reveals the ANOVA results of rut depths between two random mixtures. It is verified that the levels of influence are significant between two sets of random mixtures from the statistical analysis. The modified effects between these micro- and nanomaterials on the rutting resistance are also remarkable. This indicates that the micro- and nanomaterials in the asphalt mixtures can extraordinarily ameliorate the rutting susceptibility of modified mixtures. Synthesizing the rut depths of these modified mixtures in APA tests, the NMN material reduces the rut depths most in contrast to the other materials.

\section{Conclusions}

In this study, five kinds of micro- and nanomaterials were selected to modify the asphalt mixture based on the literature review. The properties of micro- and nanomodified asphalt mixtures were evaluated using the Superpave specification tests. These performance tests were carried out, including the dynamic modulus and APA rutting tests. The data processing methods, ANOVA and moving average, were applied to analyze the data reliability and trends, respectively. Based on the performance test and data analysis results, the following conclusions can be summarized:

(1) The addition of micro- and nanomaterials (NMN, PMN, Nanomer, MCF, and NS materials) in the asphalt mixture causes significant improvements in the rut factor $E^{*} / \sin \delta$ and dynamic modulus of the modified asphalt mixtures. This phenomenon implies that the mechanical properties of these modified asphalt mixtures are enhanced, and the rutting resistance is improved in contrast to the control mixture. The increase in the macroscopic performance in asphalt mixtures is due to different structures of micro- and nanomodified asphalt. Physical dispersions and chemical reactions of modifiers occurred with the asphalt for special characterizations of micro- and nanomaterials in the modified asphalt mixtures. In addition, from the ANOVA analysis, the NMN material has a significant effect on the improvement of the dynamic modulus compared to the other materials used in the study.

(2) The micro- and nanomaterials in the asphalt mixture result in a decrease in the rut depth of the modified mixtures in accordance with the APA rutting test data, which is consistent with the factor $E^{*} / \sin \delta$ and dynamic modulus results. The extents of the reduction in rut depths in the APA tests of modified mixtures are different. Meanwhile, the ANOVA analysis results indicate that the micro- and nanomaterials used in this study have remarkable benefits on the rutting resistance of asphalt mixtures. The NMN material in the asphalt mixtures can improve the rutting resistance the most compared to the other four types of modifiers (micro- and nanomaterials).

In summary, the use of micro- and nanomaterials (NMN, PMN, Nanomer, MCF, and NS materials) in the asphalt mixture improves the mechanical properties of these modified 
asphalt mixtures. Based on the test results of micro- and nanomaterials modified asphalt binders in our group $[14,15$, $19,20,38]$, there is an excellent agreement with the results of asphalt mixtures in this study. In addition, future work may focus on additional tests for evaluating the low-temperature performance of asphalt mixtures.

\section{Disclaimer}

Any opinion, finding, and conclusion expressed in this paper are those of the authors and do not necessarily represent the view of any organization.

\section{Conflict of Interests}

The authors declare that there is no conflict of interests regarding the publication of this paper.

\section{Acknowledgments}

The authors would like to thank Dr. David Wingard for the help of SEM testing. The experimental work was completed at the Transportation Materials Research Center at Michigan Technological University.

\section{References}

[1] C. Ouyang, S. Wang, Y. Zhang, and Y. Zhang, "Improving the aging resistance of styrene-butadiene-styrene tri-block copolymer modified asphalt by addition of antioxidants," Polymer Degradation and Stability, vol. 91, no. 4, pp. 795-804, 2006.

[2] B. V. Kok and M. Yilmaz, "The effects of using lime and styrenebutadiene-styrene on moisture sensitivity resistance of hot mix asphalt," Construction and Building Materials, vol. 23, no. 5, pp. 1999-2006, 2009.

[3] M. J. Khattak, G. Y. Baladi, and L. T. Drzal, "Low temperature binder-aggregate adhesion and mechanistic characteristics of polymer modified asphalt mixtures," Journal of Materials in Civil Engineering, vol. 19, no. 5, pp. 411-422, 2007.

[4] S.-C. Huang, R. E. Robertson, J. F. Branthaver, and J. C. Petersen, "Impact of lime modification of asphalt and freeze-thaw cycling on the asphalt-aggregate interaction and moisture resistance to moisture damage," Journal of Materials in Civil Engineering, vol. 17, no. 6, pp. 711-718, 2005.

[5] D. Lesueur, J. Petit, and H.-J. Ritter, "The mechanisms of hydrated lime modification of asphalt mixtures: a state-of-theart review," Road Materials and Pavement Design, vol. 14, no. 1, pp. 1-16, 2013.

[6] D. Lo Presti, "Recycled Tyre Rubber Modified Bitumens for road asphalt mixtures: a literature review," Construction and Building Materials, vol. 49, pp. 863-881, 2013.

[7] Z. You, J. Mills-Beale, E. Fini, S. W. Goh, and B. Colbert, "Evaluation of low-temperature binder properties of warm-mix asphalt, extracted and recovered RAP and RAS, and bioasphalt," Journal of Materials in Civil Engineering, vol. 23, no. 11, pp. 15691574, 2011.

[8] B. W. Colbert and Z. You, "Properties of modified asphalt binders blended with electronic waste powders," Journal of Materials in Civil Engineering, vol. 24, no. 10, pp. 1261-1267, 2012.
[9] Z. Vlachovicova, C. Wekumbura, J. Stastna, and L. Zanzotto, "Creep characteristics of asphalt modified by radial styrenebutadiene-styrene copolymer," Construction and Building Materials, vol. 21, no. 3, pp. 567-577, 2007.

[10] M. J. Khattak, A. Khattab, H. R. Rizvi, and P. Zhang, "The impact of carbon nano-fiber modification on asphalt binder rheology," Construction and Building Materials, vol. 30, pp. 257-264, 2012.

[11] M. J. Khattak, A. Khattab, and H. R. Rizvi, "Mechanistic characteristics of asphalt binder and asphalt matrix modified with nano-fibers," in Proceedings of the Geo-Frontiers, p. 492, ASCE, Dallas, Tex, USA, March 2011.

[12] F. Xiao, A. N. Amirkhanian, and S. N. Amirkhanian, "Influence of carbon nanoparticles on the rheological characteristics of short-term aged asphalt binders," Journal of Materials in Civil Engineering, vol. 23, no. 4, pp. 423-431, 2011.

[13] J. Cheng, J. Shen, and F. Xiao, "Moisture susceptibility of warmmix asphalt mixtures containing nanosized hydrated lime," Journal of Materials in Civil Engineering, vol. 23, no. 11, pp. 15521559, 2011.

[14] H. Yao, Z. You, L. Li et al., "Rheological properties and chemical analysis of nanoclay and carbon microfiber modified asphalt with Fourier transform infrared spectroscopy," Construction and Building Materials, vol. 38, pp. 327-337, 2013.

[15] H. Yao, Z. You, L. Li et al., "Performance of asphalt binder blended with non-modified and polymer-modified nanoclay," Construction and Building Materials, vol. 35, pp. 159-170, 2012.

[16] S. M. Marandi, M. Ghasemia, M. Tahmooresi, R. J. Kamali, and R. Taherzade, "Modification of stone matrix asphalt with nano$\mathrm{SiO}_{2}$," Journal of Basic and Applied Scientific Research, vol. 2, no. 2, pp. 1338-1344, 2012.

[17] D. Liu, Q. Luo, H. Wang, and J. Chen, "Direct synthesis of micro-coiled carbon fibers on graphite substrate using coelectrodeposition of nickel and sulfur as catalysts," Materials \& Design, vol. 30, no. 3, pp. 649-652, 2009.

[18] Z. Yang, J. Hollar, and X. Shi, "Surface-sulfonated polystyrene microspheres improve crack resistance of carbon microfiberreinforced Portland cement mortar," Journal of Materials Science, vol. 45, no. 13, pp. 3497-3505, 2010.

[19] H. Yao, Z. You, L. Li et al., "Evaluation of asphalt blended with low percentage of carbon micro-fiber and nanoclay," Journal of Testing and Evaluation, vol. 41, no. 2, pp. 278-288, 2013.

[20] H. Yao, Z. You, L. Li et al., "Rheological properties and chemical bonding of asphalt modified with nanosilica," Journal of Materials in Civil Engineering, vol. 25, no. 11, pp. 1619-1630, 2013.

[21] X. He and X. Shi, "Chloride permeability and microstructure of Portland cement mortars incorporating nanomaterials," Transportation Research Record, vol. 2070, no. 1, pp. 13-21, 2008.

[22] Z. You, J. Mills-Beale, J. M. Foley et al., "Nanoclay-modified asphalt materials: preparation and characterization," Construction and Building Materials, vol. 25, no. 2, pp. 1072-1078, 2011.

[23] M. W. Simon, K. T. Stafford, and D. L. Ou, "Nanoclay reinforcement of liquid silicone rubber," Journal of Inorganic and Organometallic Polymers and Materials, vol. 18, no. 3, pp. 364373, 2008.

[24] S. G. Jahromi and A. Khodaii, "Effects of nanoclay on rheological properties of bitumen binder," Construction and Building Materials, vol. 23, no. 8, pp. 2894-2904, 2009.

[25] K. K. M. W. Witczak, T. Pellinen, M. El-Basyouny, and H. Von Quintus, "Simple performance test for superpave mix design," NCHRP Report 465, Arizona State University, Tempe, Arizona, 2002. 
[26] M. W. Witczak, Specification Criteria for Simple Performance Tests for Rutting, Arizona State University, Tempe, Ariz, USA, 2007.

[27] S. Lee, S. Mun, and Y. Richard Kim, "Fatigue and rutting performance of lime-modified hot-mix asphalt mixtures," Construction and Building Materials, vol. 25, no. 11, pp. 4202-4209, 2011.

[28] C. W. Schwartz, R. Li, S. H. Kim, H. Ceylan, and K. Gopalakrishnan, "Sensitivity evaluation of MEPDG performance prediction," NCHRP 1-47, National Cooperative Highway Research Program, Transportation Research Board of the National Academies, Transportation Research Board, 2011.

[29] C. W. Schwartz, "Implementation of the NCHRP 1-37A design guide volume 1: summary of findings and implementation plan," Final Report, Department of Civil and Environmental Engineering, The University of Maryland, Office of Material Technology, Maryland State Highway Administration, 2007.

[30] P. D. You Zhanping, G. S. Wei, and R. Christopher Williams, Development of Specification for the Superpave Simple Performance Tests (SPT): Final Report, Michigan Department of Transportation, Lansing, Mich, USA, 2009.

[31] L. Chotirat, K. Chaochanchaikul, and N. Sombatsompop, "On adhesion mechanisms and interfacial strength in acrylonitrilebutadiene-styrene/wood sawdust composites," International Journal of Adhesion and Adhesives, vol. 27, no. 8, pp. 669-678, 2007.

[32] J. Kim, K. Lee, K. Lee, J. Bae, J. Yang, and S. Hong, "Studies on the thermal stabilization enhancement of ABS; synergistic effect of triphenyl phosphate nanocomposite, epoxy resin, and silane coupling agent mixtures," Polymer Degradation and Stability, vol. 79, no. 2, pp. 201-207, 2003.

[33] T. Sugimoto, Fine Particles: Synthesis, Characterization, and Mechanisms of Growth, Marcel Dekker, 2000.

[34] P. Ding, M. G. Orwa, and A. W. Pacek, "De-agglomeration of hydrophobic and hydrophilic silica nano-powders in a high shear mixer," Powder Technology, vol. 195, no. 3, pp. 221-226, 2009.

[35] Z. You, S. Wei Goh, and R. Christopher Williams, Development of Specification for the Superpave Simple Performance Tests (SPT): Final Report, Michigan Department of Transportation, Lansing, Mich, USA, 2009.

[36] H. Wang, Z. Dang, Z. You, and D. Cao, "Effect of warm mixture asphalt (WMA) additives on high failure temperature properties for crumb rubber modified (CRM) binders," Construction and Building Materials, vol. 35, pp. 281-288, 2012.

[37] Y. Chou, Statistical Analysis: With Business and Economic Applications, Holt, Rinehart and Winston, 1969.

[38] H. Yao, Y. Liu, Z. You, L. Li, and S. W. Goh, "Discrete element simulation of bending beam rheometer tests for asphalt binder," International Journal of Pavement Research and Technology, vol. 5, no. 3, pp. 161-168, 2012. 

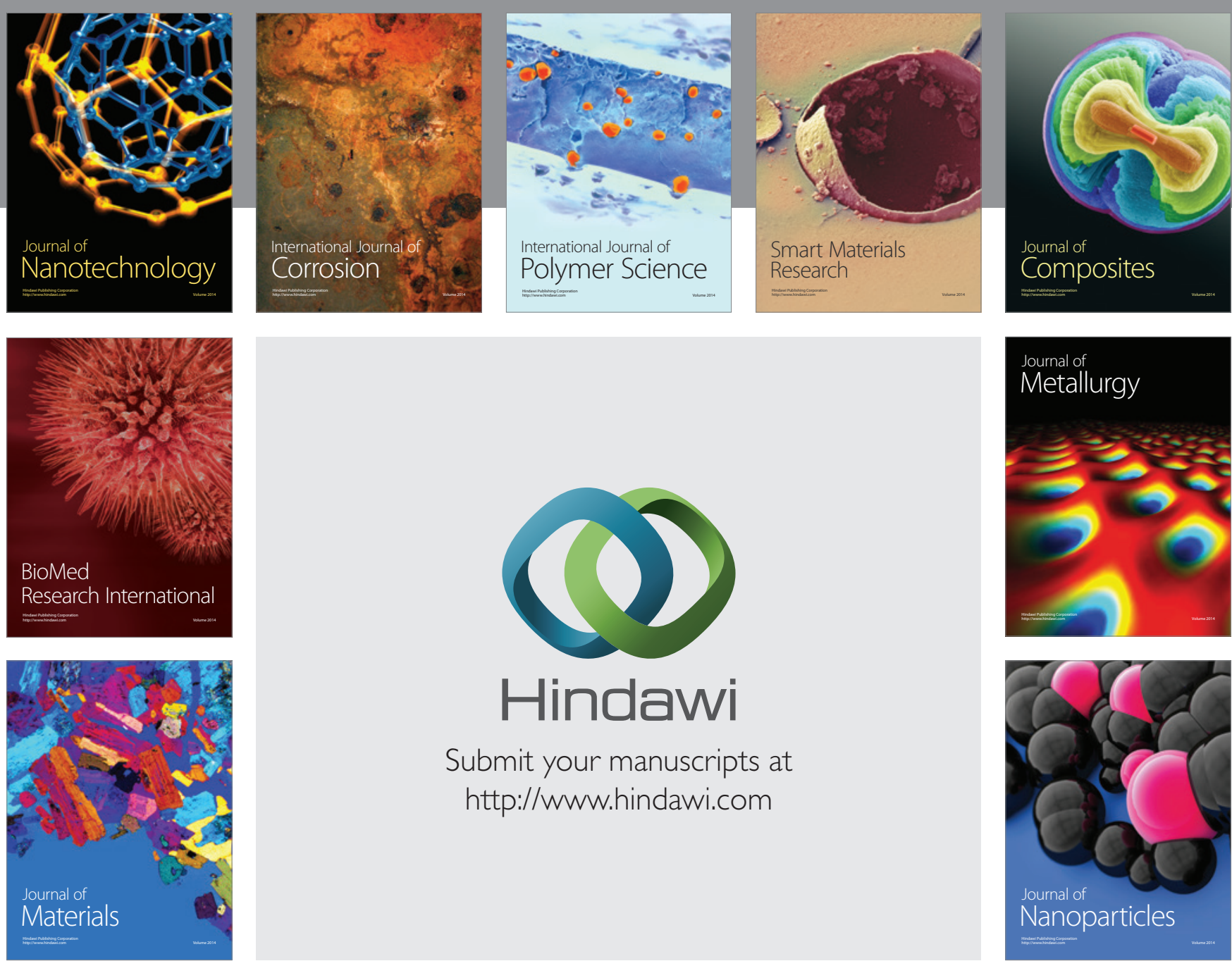

\section{Hindawi}

Submit your manuscripts at

http://www.hindawi.com

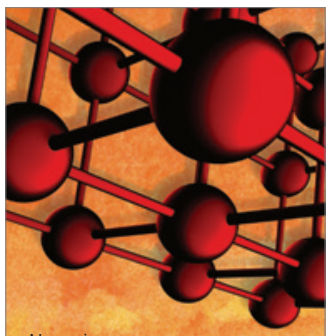

Materials Science and Engineering
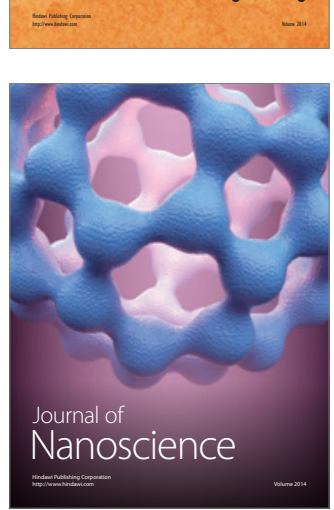
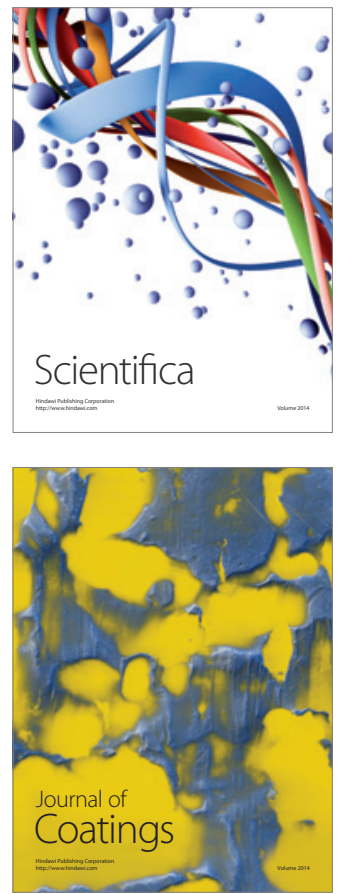
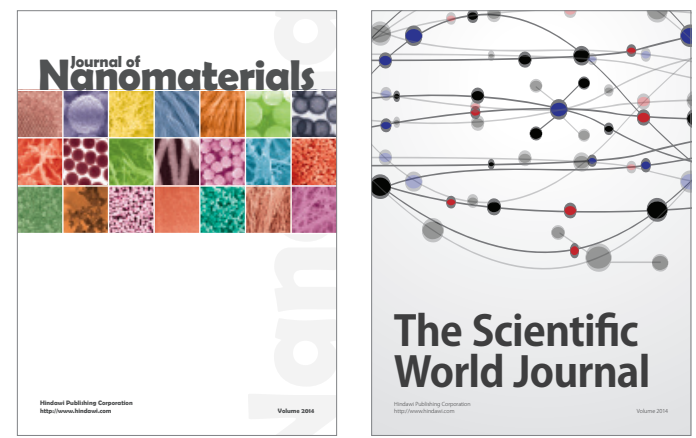

The Scientific World Journal
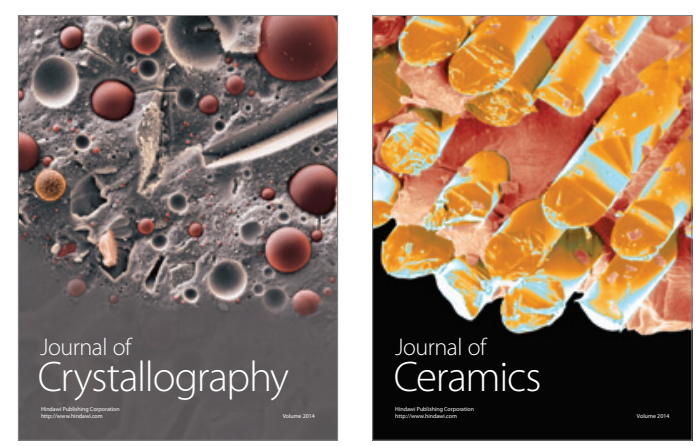
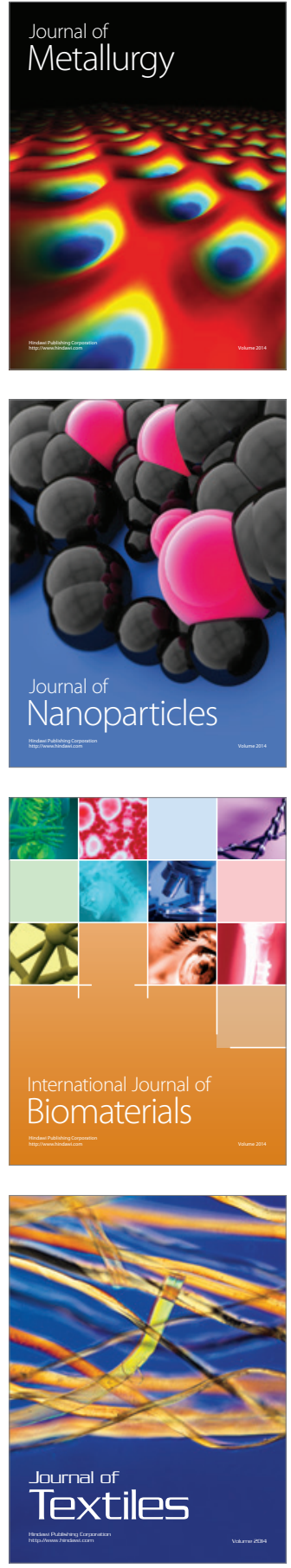